\title{
CAN TRANSITION DYNAMICS EXPLAIN THE INTERNATIONAL OUTPUT DATA?*
}

\author{
Chris Papageorgiou and Fidel P \&rez-Sebasti\$n**
}

W P-A D 2001-02

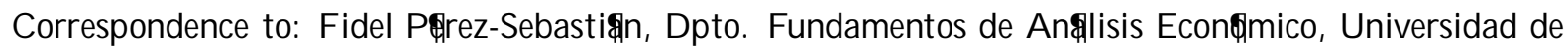
Alicante, Campus de San Vicente del Raspeig, 03071 Alicante, Spain, e-mail: ' del@merlin.fae.ua.es

E ditor: Instituto Valenciano de Investigaciones E con 4 micas, S.A.

First Edition J anuary 2001.

Dep\&sito L egal: V-518-2001

IVIE working papers o $\mathrm{Ber}$ in advance the results of economic research under way in order to encourage a discussion process before sending them to scienti ${ }^{-} \mathrm{c}$ journals for their ${ }^{-}$nal publication.

* A previous version of this paper was circulated under the title $\backslash$ Growth with Technical Change and Human Capital: Transition Dynamics Versus Steady State Predictions." We thank Craig Burnside, J ordi Caballe, Emilio Dominguez, J ohn D u \&y, T heodore Palivos, and seminar participants at the $6^{\text {th }}$ International Conference of the Society

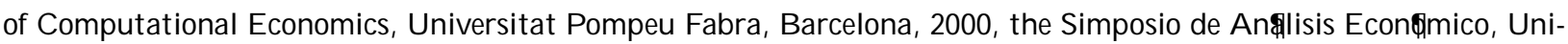
versitat A ut \&noma de Barcelona, 1999, the International Conference in E conomic Growth, A cadimia Senica, Taipei, 1999 , the $69^{\text {th }}$ Southern Economic Association meetings, New Orleans, 1999, and the Midwest Macro Conference, University of Pittsburgh, Fall 1999, for helpful comments and suggestions.

** C. Papageorgiou: Lousiana State University; F. Perez-Sebastian: University of Alicante. 


\author{
CAN TRANSITION DYNAMICS EXPLAIN \\ THE INTERNATIONAL OUTPUT DATA? \\ Chris Papageorgiou and Fidel P \&rez-Sebasti\$n
}

\begin{abstract}
This paper studies the transition dynamics predictions of an $R \& D$-based growth model, and evaluates their performance in explaining income disparities across nations. We ${ }^{-}$nd that the fraction of the observed cross-country income variation explained by the transitional dynamics of the model is as large as the one accounted by existing steady-state level regressions. Our results suggest that the traditional view of a world in which nations move along their distinct balancedgrowth paths is as likely as the one in which countries move along adjustment paths toward a common (very long-run) steady state.
\end{abstract}

K ey words: Transition Dynamics; Income Disparities; Growth. 


\section{INTRODUCTION}

In growth literature, it is common practice to study cross-country income disparities under two maintained assumptions: First, that countries have distinct long-run growth paths, and therefore cross-country disparities can be studied using steady-state analysis. Second that income disparities can arise from transitions back to the steady state, and therefore understanding cross-country income di ßerences requires the use of transitional dynamics analysis.

Since Mankiw, Romer and Weil (1992) (M RW) seminal contribution, empirical work on economic growth has primarily adopted the former assumption focusing on estimating reduced form steady-state speci ${ }^{-}$cations. ${ }^{1}$ As K lenow and R odriguez-Clare (1997) recognize, the lack of absolute convergence exhibited by the international data seems to support this practice. ${ }^{2}$ Theoretical growth models are also primarily focused on balanced-growth path analysis. Sala-i-Martin (1996) claims that the main reason to concentrate on steady states is that they are easier to analyze than transition dynamics, and therefore makes them spring boards on which to advance richer explanations of economic growth.

Even though the literature has embraced steady-state analysis, it is widely accepted that income disparities are most likely due to some combination of steady-state di ßerences and transition towards the long-run path. ${ }^{3}$ It is then important to ask the question: How much of the dispersion in per capita income can be explained by countries being away from their steady-state paths? To answer this question, we take the opposite approach to steady-state regressions: we assume that all countries approach the same balanced growth path, and that their income levels di ßer because they are at di ßerent points along the transition.

M ore speci- cally, we study the transition dynamics predictions of a growth model with technical progress, physical capital accumulation, and human capital formation, and evaluate their perfor-

\footnotetext{
${ }^{1}$ Recent contributions that use steady-state regressions include Nonneman and Vanhoudt (1996), Temple (1998), and Dinopoulos and Thompson (2000), just to name a few.

${ }^{2}$ In addition, Easterly and Kremer (1993) - nds growth rates to be highly unstable over time while country characteristics are stable. They interpret their - nding as one describing a world scenario in which countries are near their steady-state relative income levels.

${ }^{3} \mathrm{~K}$ ing and Rebelo (1993) emphasize the important role of adjustment paths in explaining growth experiences. Barro and Sala-i-Martin (1995, Ch. 11) report estimates of regional 3/4Convergence within countries that allow for a large role for transition dynamics. F inally, in an interesting paper, J ones (2000) questions whether the U.S. is actually in steady state. In particular, J ones ' nds that 80 percent of U.S. growth between 1950 i 1993 is associated with transition dynamics. He further argues that the stability of U.S. growth over the last century maybe a remarkable accident of transition dynamics, or more likely, that transition dynamics of various factors maybe well-behaved leading to a constant growth path.
} 
mance in explaining income disparities across countries. The model is a version of J ones (1995) hybrid non-scale growth framework in which sustained long-run growth depends on both exogenous labor growth and endogenous technical change. ${ }^{4}$ In our model, technological progress is enhanced through innovation and imitation, and human capital through formal schooling. The schooling technology follows the M incerian approach (M incer (1974)) that has recently been revived by Bils and K lenow (forthcoming). A $\mathrm{n}$ important feature of modeling human capital by using this speci- cation, is that it matches up with the existing cross-country data on education (average years of schooling as in, e.g. Barro and Lee (1993), and Nehru, Swanson, and Dubey (1995)).

Even though the model in this paper exhibits certain properties that can stand out in their own right the focus is on the calibration exercise. In particular, the focus is on taking the transition dynamics predictions of the model to the data. We do that by solving numerically for the transition dynamics using J udd's (1992) projection methods. Our main ${ }^{-}$nding is that transition dynamics are able to explain the cross-county income data equally well as previous studies that employ steady-state regressions. Overall, our results suggest that a world in which nations move along their balanced-growth paths is as likely as a world in which countries move along adjustment paths toward a common (very long-run) steady state.

Related work that is close to our approach \{ using calibration and taking the implications of growth models to the data \{ include Christiano (1989), King and Rebelo (1993), Chari, Kehoe, and McGrattan (1996), J ovanovic and Rob (1998), and Perez-Sebastian (2000). Like us, Funke and Strulik (2000) study transition dynamics in a model of physical capital, human capital and blueprints. They, however, study the existence of threshold levels in the parameters that switch on and $0 \circledR$ the di ßerent sectors. Finally, other growth models with multi-sector transition dynamics include Caballe and Santos (1993), Mulligan and Sala-i-M artin (1993), Ortigueira and Santos (1997), and Eicher and Turnovsky (1999b, forthcoming).

The rest of the paper is organized as follows. Section 2 presents the basic model. In this section, we establish the economic environment and examine the steady-state and transition dynamics

\footnotetext{
${ }^{4} \mathrm{~A}$ ny answer to the question motivating the paper is conditional on a model, and admittedly our proposed model is one of various candidates. Papageorgiou and Perez-Sebastian (2000) present a detailed discussion of the model that we use here, arguing that a successful model of economic growth and development is one in which both technological progress and human capital accumulation are necessary engines, and the endogenous outcome of the economic system. In particular, the authors show that the proposed model of technical change and human capital can explain rapid output growth experiences, such as J apan and South Korea, better than other existing growth frameworks. For an extensive discussion on non-scale growth models see Eicher and Turnovsky (1999a).
} 
properties of the model. The numerical analysis is presented in Section 3. In this section, we use calibration techniques to examine how well the adjustment path implied by our model " country output data. Section 4 concludes discussing the main " ndings of our work, and directions for future research.

\section{THE BASIC MODEL}

In this section we present the basic model. F irst, we outline the economic environment under which households and " rms operate. Then we solve the socially optimal problem.

\subsection{E conomic environment}

For simplicity of exposition, we focus on a centrally planned economy. ${ }^{5}$ The population in this economy consists of identical in ${ }^{-}$nitely-lived agents, and grows exogenously at rate $\mathrm{n}$ : A gents have preferences only over consumption, and are involved in three types of activities: consumption-goods production, $R \& D$ eßort, and human capital attainment. Each period, consumers are endowed with one unit of time that is allocated between working and studying.

Our model economy is characterized by the following three equations: First, at period $t$, output $\left(\mathrm{Y}_{\mathrm{t}}\right)$ is produced using labor $\left(\mathrm{L}_{\mathrm{Y}}\right)$ and physical capital $\left(\mathrm{K}_{\mathrm{t}}\right)$ according to the following aggregate Cobb-D ouglass technology:

$$
\mathrm{Y}_{\mathrm{t}}=\mathrm{A}_{\mathrm{t}}^{\gg}\left(\mathrm{h}_{\mathrm{t}} \mathrm{L}_{\mathrm{Yt}}\right){ }^{\mathrm{I}_{\mathrm{i}}{ }^{\circledR}} \mathrm{K}_{\mathrm{t}}^{\circledR} ; 0<\circledast<1 ; \gg>0 ;
$$

where $h_{t}$ represents the e Rectiveness of average human capital level on labor; $®$ is the share of capital; » is a technology externality; and $A_{t}$ is the economy's technical level.

Second, the $R \& D$ equation that determines technological progress is given by

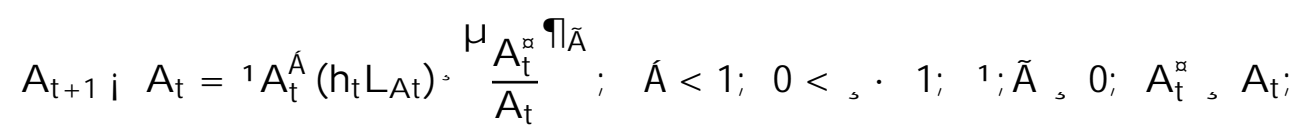

where $L_{A t}$ is the portion of labor employed in the $R \& D$ sector at time $t$; $A_{t}^{\alpha}$ is the worldwide stock of existing technology at $t$, which grows exogenously at rate $g_{A x}$; Á represents an externality due to the stock of existing technology; and, captures the existence of decreasing returns to $R \& D$ eßort. Our $R \& D$ equation includes a catch-up term $\frac{A_{t}^{a}}{A_{t}} \tilde{A}$, where $\tilde{A}$ is a technology gap parameter. The

\footnotetext{
${ }^{5}$ It is well known that in models with externalities like ours, appropriate policies by the social planner can achieve the ${ }^{-}$rst best. We assume that these policies are imposed in our economy and focus on the social planner's problem.
} 
catch-up term captures the idea that the greater the technology gap between a leader and a follower, the higher the potential of the follower to catch up through imitation of existing technologies. ${ }^{6}$

Third, we have the schooling equation that determines the way by which human capital is formed. Human capital technology is of particular interest in our model and deserves careful consideration. Since our aim is to take the model to the data then our speci ${ }^{-}$cation ought to be one that maps the available data on average years of education to the stock of human capital. Using the Mincerian interpretation seems to deliver such a speci- cation. This representation follows Bils and K lenow (forthcoming), who suggest that the Mincerian speci ${ }^{-}$cation of human capital is the appropriate way to incorporate years of schooling in the aggregate production function. Following their approach, human capital per capita is given by

$$
h_{t}=e^{f\left(S_{t}\right)}
$$

where $f\left(S_{t}\right)={ }^{\prime} S_{t}^{-}, '>0,{ }^{-}>0$; and $S_{t}$ is the labor force average years of schooling at date $t$. The derivative $f\left(S_{t}\right)$ represents the return to schooling estimated in a Mincerian wage regression: an additional year of schooling raises a worker's e \pm ciency by $f\left(S_{t}\right){ }^{7}$

Next, we are concerned with the behavior of $S_{t}$. In particular, we derive a law of motion of $S_{t}$ that is consistent with the following two desirable properties: (a) the evolution of $S_{t}$ depends on the share of people in the schooling sector; (b) in steady state, $S_{t}$ is constant. As it is counter-factual to assume that $S_{t}$ grows inde ${ }^{-}$nitely, the second property indicates that at steady state the average years of education reaches $a^{-}$xed number. ${ }^{8}$

We assume that, each period, agents allocate time to human capital formation only after output production has taken place. Let $L_{H t}$ be the total amount of labor invested in schooling in the economy at date t. Assume that at some point in time, say period 1, the average educational attainment equals zero. Next period, given that consumers live for ever, the average years of schooling will be $S_{2}=\frac{L_{H 1}}{L_{2}}$, where $L_{t}$ is the labor size at date $t$. In period $3, S_{3}=\frac{L_{H_{1}}+L_{H 2}}{L_{3}}$, and

\footnotetext{
${ }^{6} T$ he notion and formulation of the catch-up eßect is due to Veblen (1915), and Gerschenkron (1962). Nelson and Phelps (1966) were the ${ }^{-}$rst to construct a formal model based on the catch-up term.

${ }^{7} \mathrm{M}$ incer (1974) estimates the following wage regression equation:

$$
\mathrm{W}_{\mathrm{i}}={ }^{-}{ }_{0}+{ }^{-}{ }_{1}(\mathrm{SCHOOL}) \mathrm{i}+{ }^{-}{ }_{2}(\text { EXPERIENCE })_{i}+{ }^{-}{ }_{3}(\text { EXPERIENCE })_{i}^{2}+{ }_{i} ;
$$

where $w_{i}$ is the log wage for individual $i, S C H O O L$ is the number of years in school, EXPERIENCE is the number of years of work experience, and " is a random disturbance term. For the original discussion on Mincerian wage regressions see $M$ incer (1974). For recent discussion of the advantages of the $M$ incerian approach in growth modeling and estimation, see Bils and K lenow (forthcoming), and K rueger and Lindahl (1998).

${ }^{8}$ For further discussion on this issue, see J ones $(1996,1997)$.
} 
so on. Hence, the average educational attainment can be written as

$$
S_{t}=\frac{P_{t_{i} 1} L_{H j}}{L_{t}} \text {. }
$$

From equation (4), we can derive the law of motion of the average educational attainment as follows:

$$
\begin{aligned}
S_{t+1} i S_{t} & =\frac{P_{t} L_{H j}}{L_{t+1}} i \frac{P_{t i 1} L_{H j}}{L_{t}} ; \\
& =\frac{1}{1+n} \frac{L_{H t}}{L_{t}} i n S_{t}:
\end{aligned}
$$

Notice that the above motion equation possesses the two desirable properties mentioned above: the evolution of $S_{t}$ depends on the share of people in education, $\frac{L_{H}}{L}$, and average years of schooling at steady state, $\mathrm{S}_{\mathrm{ss}}$; reaches an upper bound remaining constant thereafter. The second property holds because, as will be clear later, the ratio $\frac{L_{H}}{L}$ is invariant at steady state; dividing expression (5) by $S_{t}$, we can then easily see that variable $S$ can grow at a constant rate only if $S$ is a constant.

\subsection{Social planner's problem}

Let $C_{t}$ be the amount of aggregate consumption at date $t$. A central planner would choose the sequences $f C_{t} ; S_{t} ; A_{t} ; K_{t} ; L_{Y t} ; L_{A t} ; L_{H} g_{t=0}^{1}$ so as to maximize the lifetime utility of the representative consumer subject to the feasibility constraints of the economy, and the initial values $L_{0} ; K_{0}$; $S_{0}$; and $A_{0}$. The problem is stated as follows:

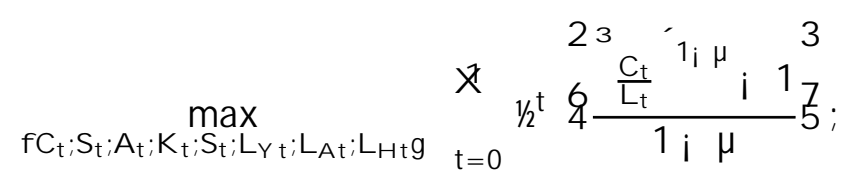

subject to,

$$
\begin{aligned}
& Y_{t}=A_{t}^{»} e^{3}{ }^{f\left(S_{t}\right)} L_{Y t}{ }^{\prime}{ }^{i}{ }^{\circledR} K_{t}^{\circledR} ; \\
& \mathrm{I}_{\mathrm{t}}=\mathrm{K}_{\mathrm{t}+1 \mathrm{i}} \quad\left(1 \mathrm{i} \# \mathrm{~K}_{\mathrm{t}}=\mathrm{Y}_{\mathrm{t}} \mathrm{i} \mathrm{C}_{\mathrm{t}}\right. \text {; } \\
& A_{t+1} i A_{t}={ }^{1} A_{t}^{A^{3}} e^{f\left(S_{t}\right)} L_{A t} \cdot{ }^{\mu}{ }^{\mu} \frac{A_{t}^{x}}{A_{t}}{ }^{n} \text {; } \\
& \mathrm{S}_{\mathrm{t}+1} \text { i } \mathrm{S}_{\mathrm{t}}=\frac{1}{1+\mathrm{n}}^{\text {ी }}{ }^{\mu} \frac{\mathrm{L}_{\mathrm{H}}}{\mathrm{L}_{\mathrm{t}}} \text { i } \mathrm{nS}_{\mathrm{t}} \text {; } \\
& L_{t}=L_{Y t}+L_{A t}+L_{H t} \text {; }
\end{aligned}
$$




$$
\begin{gathered}
\frac{L_{t+1}}{L_{t}}=1+n ; \text { for all } t \\
\frac{A_{t+1}^{\alpha}}{A_{t}^{\alpha}}=1+g_{A^{x}} ; \\
L_{0} ; S_{0} ; K_{0} ; A_{0} \text { given, }
\end{gathered}
$$

where $\mu$ is the inverse of the intertemporal elasticity of substitution; $1 / 2$ is the discount factor; and \pm is the depreciation rate of physical capital. Equation (8) is a feasibility constraint as well as the law of motion of the stock of physical capital; it says that, at the aggregate level, domestic output must equal consumption plus physical capital investment, $I_{t}$. Equation (11) is the labor constraint; the labor force $\{$ that is, the number of people employed in the output and the $R \& D$ sectors $\{$ plus the number of people going to school must be equal to the labor/ population stock.

The optimal control problem can be stated as follows:

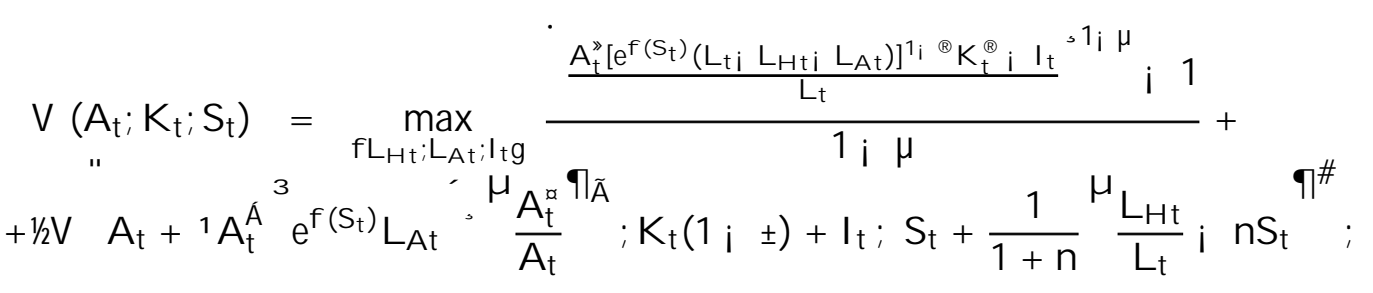

where $V\left(\phi\right.$ is a value function; $L_{H t} ; L_{A t} ; I_{t}$ are the control variables; and $A_{t} ; K_{t} ; S_{t}$ are the state variables. Solving the optimal control problem gives the Euler equations that characterize the optimal allocation of labor in human capital investment, in $R \& D$ investment, and in consumption/ physical capital investment respectively as follows:

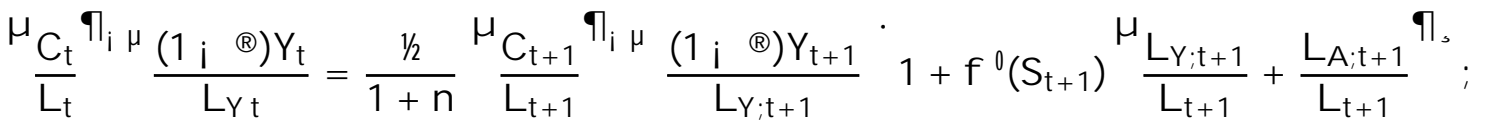

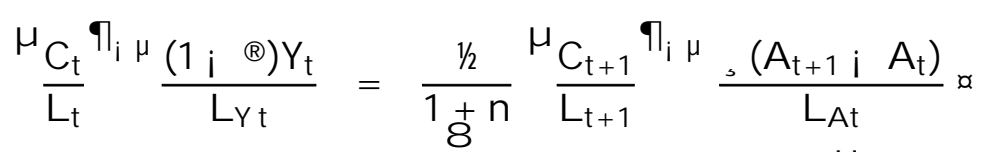

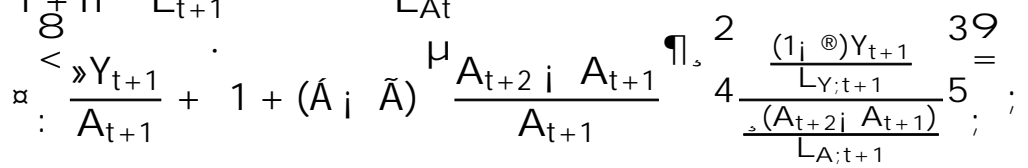

$$
\begin{aligned}
& { }^{\mu}{\frac{C_{t}}{L_{t}}}^{\eta_{i} \mu}=\frac{1 / 2}{1+n}^{\mu}{\frac{C_{t+1}}{L_{t+1}}}^{\bigcap_{i} \mu^{\prime}} \frac{\circledast Y_{t+1}}{K_{t+1}}+(1 ;)^{\prime}:
\end{aligned}
$$

At the optimum, the planner must be indi Rerent between investing one additional unit of labor in schooling, $R \& D$, and ' nal output production. The LHS of equations (15) and (16) represent the return from allocating one additional unit of labor to output production. The RHS of equation 
(15) is the discounted marginal return to schooling, taking into account labor growth. The RHS term in brackets arises because human capital determines the e Rectiveness of labor employed in output production as well as in $R \& D$. The RHS of equation (16) is the return to $R \& D$ investment. An additional unit of $R \& D$ labor generates $\frac{\left(A_{t+1 i} A_{t}\right)}{L_{A t}}$ new ideas for new types of producer durables. Every new design increases next period's output by $\frac{\| Y_{t+1}}{A_{t+1}}$ and $R \& D$ production by $\frac{d A_{t+2}}{d A_{t+1}}$

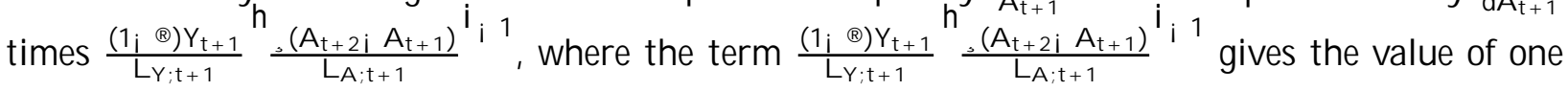
additional design that equalizes labor wages across sectors. Euler equation (17) is standard. It says that the planner is indi ßerent between consuming one additional unit of output today and converting it into capital, thus consuming the proceeds tomorrow.

\subsection{Steady-state growth}

We now derive the model's balanced-growth path. Solving for the interior solution, equation (11) implies that in order for the labor allocations to grow at constant rates, $L_{H t}, L_{Y t}$ and $L_{A t}$ must all increase at the same rate as $\mathrm{L}_{\mathrm{t}}$. This means that the ratio $\frac{\mathrm{L}_{\mathrm{Ht}}}{\mathrm{L}_{\mathrm{t}}}$ is invariant along the balancedgrowth path. Hence, equation (10) implies that, at steady-state (ss), $\mathrm{S}_{\mathrm{ss}}$ is constant and equals

$$
\mathrm{S}_{\mathrm{SS}}=\frac{\mathrm{u}_{\mathrm{H} ; \mathrm{sS}}}{\mathrm{n}}
$$

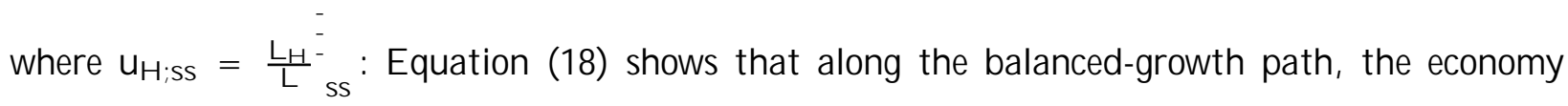
invests in human capital just to provide new generations with the steady-state level of schooling. This is consistent with work by J ones (1996, 1997), where growth regressions are developed from

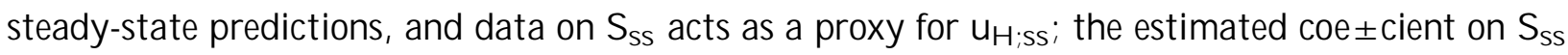
in part re ${ }^{\circ}$ ects the parameter $\frac{1}{n}$ in our framework.

Let lower case letters denote per capita variables, and $g_{x}=G_{x}$ i 1 denote the growth rate of $x$. The aggregate production function, given by equation (7), combined with the steady-state condition $g_{Y ; s s}=g_{K} ; s s$ delivers the gross growth rate of output as a function of the gross growth rate of technology as

$$
G_{Y ; s s}=\left(G_{A ; s s}\right) \frac{\#}{1 i_{i} \circledast}(1+n):
$$

Since $G_{A ; s s}$ is a constant, it follows from equation (2) that

$$
\mathrm{G}_{A ; S S}=(1+n) \cdot\left(G_{A^{x} ; s S}\right)^{\frac{»}{1 i^{\oplus}}} \frac{1}{1+A_{i} A}:
$$


Figure 1: Relationship between $\mathrm{G}_{\mathrm{A} ; \mathrm{ss}}$ and $\mathrm{G}_{\mathrm{A}^{\mathrm{x}} ; \mathrm{ss}}$

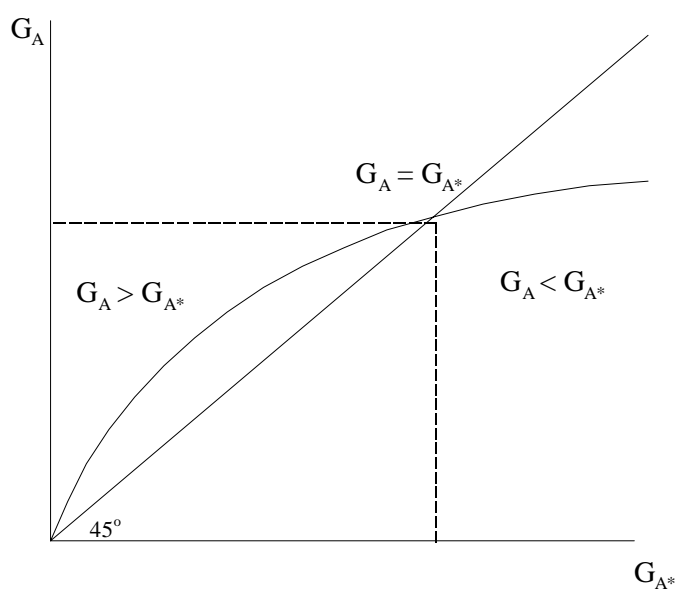

Equation (20) shows the relationship between the technology frontier growth rate and the technology growth rate of the model economy. Figure 1 illustrates this relationship.N otice that since the ratio $\frac{\tilde{A}}{1+A_{i} A}<1$; the function is concave with a unique point at which

$$
G_{A ; S S}=G_{A^{x} ; s S}=(1+n) \overline{T_{i A}}:
$$

The gross rate $G_{A ; s s}$ cannot be larger than $G_{A^{x} ; \text { ss }}$ otherwise $A_{t}$ will eventually become bigger than $A_{t}^{\alpha}$, and this has been ruled out by assumption. But $G_{A ; s s}$ can be smaller than $G_{A^{x} ; s s .}$ For simplicity, we focus on the special case in which all countries grow at the same rate at steady state; that is, we assume that $G_{A^{x} ; s s}$ is given by expression (21), and therefore so is $G_{A ; s s .}{ }^{9}$ This in turn implies that

$$
G_{Y ; S S}=G_{C ; s S}=G_{K ; s S}=(1+n) \frac{n\left(11_{i} \otimes\left(11_{i} A\right)\right.}{:}
$$

Consistent with J ones (1995) our balanced-growth path is free of scale e®ects. The reason why our model's long-run growth is equivalent to that of J ones even in the presence of a schooling sector, is that at steady state the mean years of education, $\mathrm{S}_{\mathrm{t}}$; reaches a constant level $\mathrm{S}_{\mathrm{ss}}$.

\footnotetext{
${ }^{9}$ Alternatively, we could assume that technology leader economy is the one that moves the world technological frontier according to equation (2) which now reduces to

$$
A_{t+1}^{a} i A_{t}^{a x}={ }^{1} A_{t}^{a A ́}\left(h_{A t}^{a} L_{A t}^{a x}\right) \cdots
$$

where now $\frac{A_{t}^{a}}{A_{t}}=1$ because imitation is not possible at the frontier; and denotes the value which variables take in the leading country. In such case $G_{A}^{\alpha}=1+g_{A}^{\alpha}=\left(1+n^{\alpha}\right) \Gamma_{A}^{A}$ as in J ones (1995). A ssuming that $n=n^{\alpha}$, and substituting $G_{A}^{a}$ into equation (20) delivers equation (21).
} 


\subsection{Labor shares in output, $R \& D$, and schooling}

Next, we derive the steady-state shares of labor in the three sectors of the economy. Let $u_{x}=\frac{L_{x}}{L}$ be the fraction of labor devoted to activity $X, 8 X=H ; Y ; A$. Euler equation (15) combined with the balanced-growth equation (22) delivers the steady-state share of labor in schooling as

$$
\begin{aligned}
& u_{H ; s s}=1 i \frac{{ }^{2} G_{y ; j s s}^{\mu_{i}} 1^{3} \frac{1+n}{1 / 2} i^{\prime} 1^{3}}{\left.f q S_{s s}\right)} ; \text { if } \frac{G_{y ; s s}^{\mu_{i}} 1^{3} \frac{1+n}{1 / 2} i^{\prime} 1}{f^{q}\left(S_{s s}\right)} \cdot 1 ; \\
& =0 \text { otherwise. }
\end{aligned}
$$

As usual, the steady-state share of labor in schooling is positively related with the return to education $f\left(S_{s s}\right)$.

Euler equation (16) combined with balanced-growth condition (22) delivers the steady-state labor share in $R \& D$ as

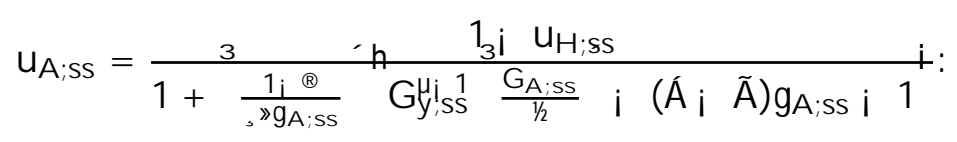

Finally, the steady-state share of labor in output production is simply derived from the labor constraint and is given by

$$
u_{Y ; s S}=1 ; \quad u_{H ; s S}+u_{A ; s s}:
$$

\subsection{Transition Dynamics}

The aggregate production function, equation (7), suggests that we normalize variables by the term

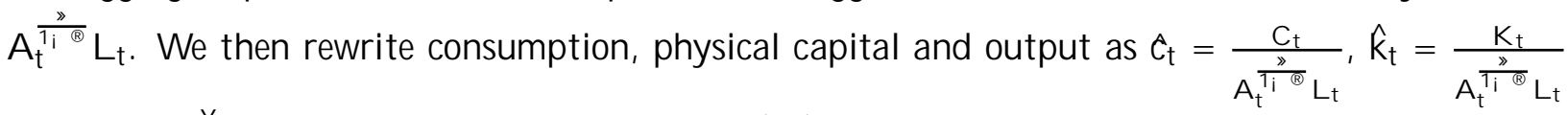
and $\hat{y_{t}}=\frac{Y_{t}}{A_{t}^{P_{i}^{+} L_{L}} L_{t}}$, respectively. Using equation (15) gives

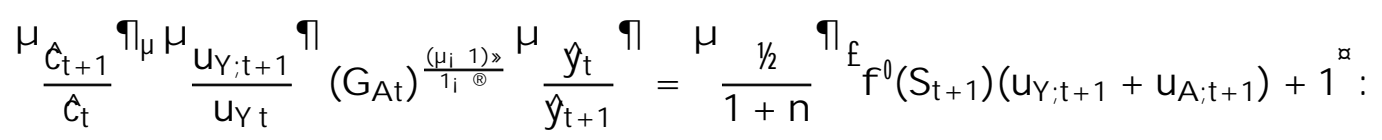

×rom the $R \& D$ equation (2), we get that

$$
G_{A t}=\frac{A_{t+1}}{A_{t}}=1+\dot{A} e^{f\left(S_{t}\right)} U_{A t}^{i} \cdot T^{\left(1+\tilde{A}_{i} \dot{A}\right)}
$$


where $T=\frac{A_{t}^{q}}{A_{t}}$; and $\grave{A}={ }^{1}\left(A_{t}^{q}\right)^{A_{i}}{ }^{1} L_{t}$, which is a constant. ${ }^{10}$ From equation (16) we get that

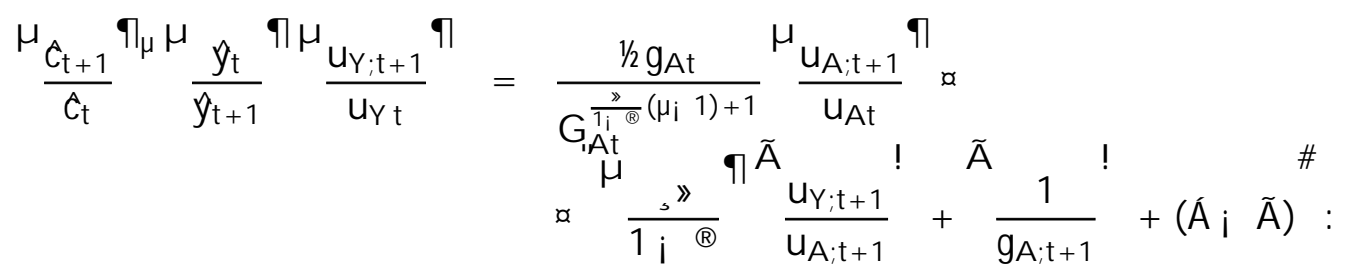

Finally, from equation (17) we get

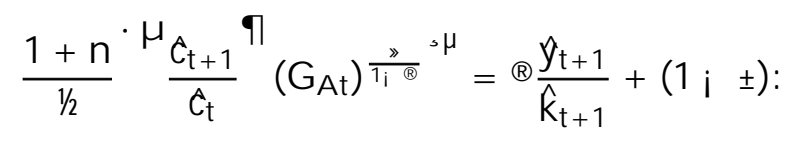

The system that determines the dynamic equilibrium normalized allocations are formed by the conditions associated with three control and three state variables as follows:

Control Variables:

1. Euler equation for labor share in schooling, $\mathrm{u}_{\mathrm{H} t}$ : Eq. (26).

2. Euler equation for labor share in $R \& D, u_{A t}$ : Eq. (28).

3. Euler equation for consumption, $\hat{\mathrm{C}}_{\mathrm{t}}$ : Eq. (29).

Subject to the constraint $u_{Y t}=1 ; u_{A t} i u_{H t}$ :

State Variables:

1. Law of motion of human capital, $\mathrm{S}_{\mathrm{t}}$ : Eq. (5).

2. Law of motion of technology, $A_{t}$ : Eq. (27).

3. Law of motion of physical capital

$$
(1+n) \hat{K}_{t+1}\left(G_{A t}\right)^{\frac{m}{1 i}}=\left(1 ; \quad \# \hat{K_{t}}+\hat{y_{t}} i \quad \hat{C_{t}} ;\right.
$$

where

$$
\mathrm{T}_{\mathrm{t}+1}=\mathrm{T}_{\mathrm{t}}{ }^{\mu} \frac{\mathrm{G}_{\mathrm{A}^{\mathrm{x}} \mathrm{t}}}{\mathrm{G}_{\mathrm{At}}}
$$

and

$$
\hat{y_{t}}=\hat{k}_{t}^{\circledR}{ }^{h}{ }^{f\left(S_{t}\right)} u_{Y t}{ }^{i}{ }_{1 i}{ }^{\circledR}:
$$

\footnotetext{
${ }^{10}$ To show that $\grave{A}$ is constant requires some algebra. Rewriting the equality in its gross growth form, $\frac{\grave{A}_{t+1}}{A_{t}}=$ $G_{A^{a} t}^{A_{i}{ }^{1}}(1+n)^{\cdots}$; and given that $G_{A^{a} t}=G_{A ; s s}=(1+n)^{\overline{T_{i}^{A}}}$; it follows that $\frac{\dot{A}_{t+1}}{A_{t}}=1$. Notice that had $A_{t}^{x}$ not grown according to equation (21), À could not be constant, making the simulation exercise much more di \pm cult to implement.
} 


\section{NUMERICAL ANALYSIS}

This section presents the main results of the paper. We ${ }^{-}$rst assign values to the parameters. Then, we simulate the transition dynamics, and take their predictions to the data. To solve the dynamics equation system, stated on page 12, we follow J udd (1992), approximating the policy functions employing high-degree polynomials in the state variables. ${ }^{11}$

\subsection{Calibration}

Table 1 shows the parameter values used to carry out the simulations. We choose a value of 0:06 for the depreciation rate $(\sharp$, and a value of 1:016 for the steady-state gross growth rate of income $\left(G_{y ; s s}\right)$, the average number in the Bils and Klenow's (forthcoming) 91-country sample. We assign values of $0: 36$ to the capital-share of output $(\AA)$ and $0: 96$ to the discount factor $(1 / 2$, which are standard in the literature. We set the growth rate of the population (n) to 1:16 percent per year, which is the average growth rate of the labor force in the G-5 countries (France, West Germany, J apan, the United Kingdom, and the United States) during the period 1965-1990. Regarding the value of the elasticity of output with respect to the technology, Grilliches (1988) reports estimates of » between 0:06 and 0:1. We follow Eicher and Turnovsky (1999b) and set »=0:1.

Table 1: Parameter values used in the simulations

\begin{tabular}{cllllll}
\hline \hline$\circledR$ & 0.36 & & 0.1 & $\mathrm{~S}_{\mathrm{SS}}$ & 12.5 \\
$1 / 2$ & 0.96 & & $\mathrm{G}_{\mathrm{y}}$ & 1.016 & & 0.69 \\
\pm & 0.06 & & & 0.5 & - & 0.43 \\
$\mathrm{n}$ & 0.0116 & $\mathrm{~A}$ & 0.94 & $\mu$ & 1.28 \\
\hline \hline
\end{tabular}

It is not clear what the steady-state value of the average educational attainment ought to be given that mean years of schooling have been increasing over the last decades in most developed countries. We choose to set $\mathrm{S}_{\mathrm{SS}}$ to $12: 5$, to match the 1993 U.S. ${ }^{-}$gure. Equations (23) and (18) imply that the inverse of the intertemporal elasticity of substitution $(\mu)$ must then equal 1:28,

\footnotetext{
${ }^{11}$ T he parameters of the approximated decision rules are chosen to (approximately) satisfy the E uler equations over a number of points in the state space, using a nonlinear equation solver. A Chebyshev polynomial basis is used to construct the policy functions, and the zeros of the basis form the points at which the system is solved; that is, we use the method of orthogonal collocation to choose these points. Finally, tensor products of the states variables are employed in the polynomial representations. This method has proven to be highly e \pm cient in similar contexts. For example, for the one-sector growth model, J udd (1992) ' nds that the approximated values of the control variables disagree with the values delivered by the true policy functions by no more than one part in 10,000 .
} 
Table 2: Variable values used to calibrate $\tilde{A}$, and accuracy measures

\begin{tabular}{|c|c|c|c|c|c|c|c|c|c|c|c|}
\hline \multirow[b]{2}{*}{ Country } & \multirow[b]{2}{*}{$\tilde{A}$} & \multicolumn{3}{|c|}{ Initial Relative Levels } & \multirow{2}{*}{$\begin{array}{l}\text { In } 1990 \\
\text { Y per } \\
\text { worker }\end{array}$} & \multicolumn{3}{|c|}{ A verage Error ${ }^{x}(\%)$} & \multicolumn{3}{|c|}{ Max. $\operatorname{Error}^{\alpha}(\%)$} \\
\hline & & $\begin{array}{l}\mathrm{K} \text { per } \\
\text { worker }\end{array}$ & $\begin{array}{c}\mathrm{S} \\
\text { years }\end{array}$ & $\begin{array}{l}\text { Y per } \\
\text { worker }\end{array}$ & & C & $\mathrm{U}_{Y}$ & $\mathrm{u}_{\mathrm{A}}$ & $\mathrm{C}$ & $\mathrm{u}_{\mathrm{Y}}$ & $\mathrm{u}_{\mathrm{A}}$ \\
\hline Japan & $0: 21$ & $16: 9 \%$ & $10: 2$ & $20: 6 \%$ & $60: 3 \%$ & $0: 01$ & $0: 02$ & $0: 01$ & 0:04 & $0: 09$ & $0: 07$ \\
\hline Korea & $0: 26$ & $11: 6 \%$ & $3: 2$ & 11:0\% & $42: 2 \%$ & 0:08 & $0: 23$ & 0:09 & $0: 35$ & 1:16 & $0: 45$ \\
\hline Non-oil & $0: 21$ & $5: 4 \%$ & $2: 7$ & $10: 4 \%$ & & $0: 19$ & $0: 49$ & $0: 14$ & $0: 89$ & $2: 45$ & $0: 60$ \\
\hline sample & $0: 26$ & $5: 4 \%$ & $2: 7$ & $10: 4 \%$ & & $0: 18$ & $0: 48$ & $0: 15$ & 0:87 & 2:38 & $0: 64$ \\
\hline
\end{tabular}

$\bar{c}$ We assess the Euler equation error over 10,000 state-space points using the approximated rules. For each variable, the measure gives the current value decision error that agents using the approximated rules make, assuming that the (true) optimal decisions were made in the previous period.

which is well within the empirical estimates. ${ }^{12}$ Following Bils and K lenow (forthcoming), we use Psacharopoulos' (1994) cross-country sample on average educational attainment and Mincerian coe \pm cients to estimate' and ${ }^{-}$. Given $\mathrm{f}(\mathrm{S})=\mathrm{C}^{\prime} \mathrm{S}^{-}$, we can construct the regression

$$
\ln \left(\mathrm{M} \mathrm{incer}_{i}\right)=a+b \ln \mathrm{S}_{i}+{ }{ }_{i} ;
$$

where $M$ incer ${ }_{i}=f q\left(S_{i}\right)$ is the estimated Mincerian coe \pm cient for country $i$; $a$ and bequal $\ln \left({ }^{\prime-}\right)$ and $\left({ }^{-} \mathrm{i} 1\right)$, respectively; and ${ }{ }_{i}$ is a disturbance term. We obtain ${ }^{\prime}=0: 69$ and ${ }^{-}=0: 43$.

Finally, we calibrate the $R \& D$ technology parameters. We set, = 0:5 and using equation (21) we recover the value of $A=0: 94 .{ }^{13}$ Following Parente and Prescott (1994), we calibrate the parameter $\tilde{A}$ to replicate miraculous experiences. ${ }^{14}$ In particular, we choose $\tilde{A}$ so as to reproduce the relative output per worker path between 1960 and 1990 in J apan and between 1963 and 1990 in S. K orea. ${ }^{15 ; 16}$ The former development experience gives a value for $\tilde{A}$ of 0:21, whereas the latter implies that $\tilde{A}$ equals $0: 26$. The initial values of the stock variables and the output data used to calibrate $\tilde{A}$, as well as the accuracy measures are provided in table 2 .

\footnotetext{
${ }^{12}$ Estimates of $\mu$ by Hall (1998), and Attanasio and Weber (1993) range from 1 to 3:5.

${ }^{13} \mathrm{E}$ stimates of , found in the literature vary from $0: 2$ to $0: 75$, so we carried out a sensitivity analysis with, taking the values $0: 25,0: 5$, and 0:75. Since the results we obtain are almost identical, we choose to concentrate on the intermediate case.

${ }^{14} \mathrm{~A}$ s in Parente and P rescott (1994), we smooth the data series involved in the calibration of Ã using the HodrickPrescott ${ }^{-}$Iter with the smoothing parameter equal to 25.

${ }^{15} \mathrm{~S}$. Korea's rapid convergence toward U.S. income levels began around 1963. J apanese convergence, on the other hand, started right after W WII. Unfortunately, the J apanese Education Department does not possess estimates of the average educational attainment before 1960. We are grateful to Tomoya Sakagami who has attempted to obtain these data for us.

${ }^{16} \mathrm{~A} / \mathrm{l}$ al ong the paper, relative values are taken with respect to U.S. levels.
} 


\subsection{Can transition dynamics explain the cross-country output data?}

The literature has shown that level regressions based on steady-state conditions can explain an important fraction of the observed output variation across nations. In particular, MRW ${ }^{-}$nd that di ßerences in physical capital investment, human capital investment, and population growth can account for almost 80 percent of the cross-country variation of income per worker. In this section, we perform two experiments. First, we study how well the adjustment path implied by our model - ts the cross-country output data. Second, we propose a similar in spirit exercise to that of M RW which however tries to assess how much of the cross-country output variation can be explained by transition dynamics. ${ }^{17}$

To carry out the ${ }^{-}$rst experiment, we need to estimate the policy rules that take state variables from given initial values to the steady state. Doing so requires the following two conditions: (a) given that the further away we move from the balanced-growth path the lower the accuracy degree of the numerical approximation, we choose the initial values so that the numerical approximation provides a maximum-error measure of about 2 percent (see table 2); (b) start the adjustment paths inside the cloud of cross-country observations that compose our comprehensive sample. ${ }^{18}$ Given conditions (a) and (b), we pick an initial value for the relative physical capital stock per worker of 5:4 percent, an initial value for the average educational attainment of 2:7 years, and an initial value for relative total factor productivity (TFP) of 55:2 percent so as to generate a relative GDP per worker level of 10:4. 19;20

Figure 2 depicts $0{ }^{\circledR}$-steady-state predictions for physical capital, average years of schooling, TFP, interest rates, and investment rates, along with the cross-sectional data. With ${ }^{-}$xed initial and 'nal values of the state variables, the question is how well the transition path follows the data

\footnotetext{
${ }^{17}$ In addition we have investigated the asymptotic speed of convergence implied by the model $\{$ the rate by which a country's output converges to its balanced growth path once the country is su \pm ciently close to its long-run equilibrium. In our model, this speed is given by the largest eigenvalue among those contained in the unit circle. Parameter values in the neighborhood of those employed in our calibration deliver speeds of convergence that vary between 1:06\% i 2:08\%; consistent with most empirical evidence. In addition, our results are consistent with the ${ }^{-}$nding of Eicher and Turnovsky (1999b), that moving from one-sector to multi-sector non-scale growth models with endogenous technological change leads to severe reduction in the asymptotic speed of convergence, and allows convergence speeds to vary across time and variables.

${ }^{18}$ O ur comprehensive sample (79 countries) consists of the MRW's non-oil nations for which average years of schooling per worker are available from the STARS (World Bank) database, minus Ireland, which is eliminated from the sample due to implausibly high schooling - gures. For further discussion on the data, see the Data Appendix.

${ }^{19} \mathrm{~N}$ otice that for relative GDP per worker level of 10:4 our numerical approximation commits a maximum error of 2:45 percent in accordance to condition (a), see table 2.

${ }^{20}$ In our simulation exercise, TFP is broadly $\mathrm{de}^{-}$ned and includes everything not already captured by the other two stock variables ( $\mathrm{S}$ and $\mathrm{K}$ ).
} 
Figure 2: A djustment paths for the non-oil sample
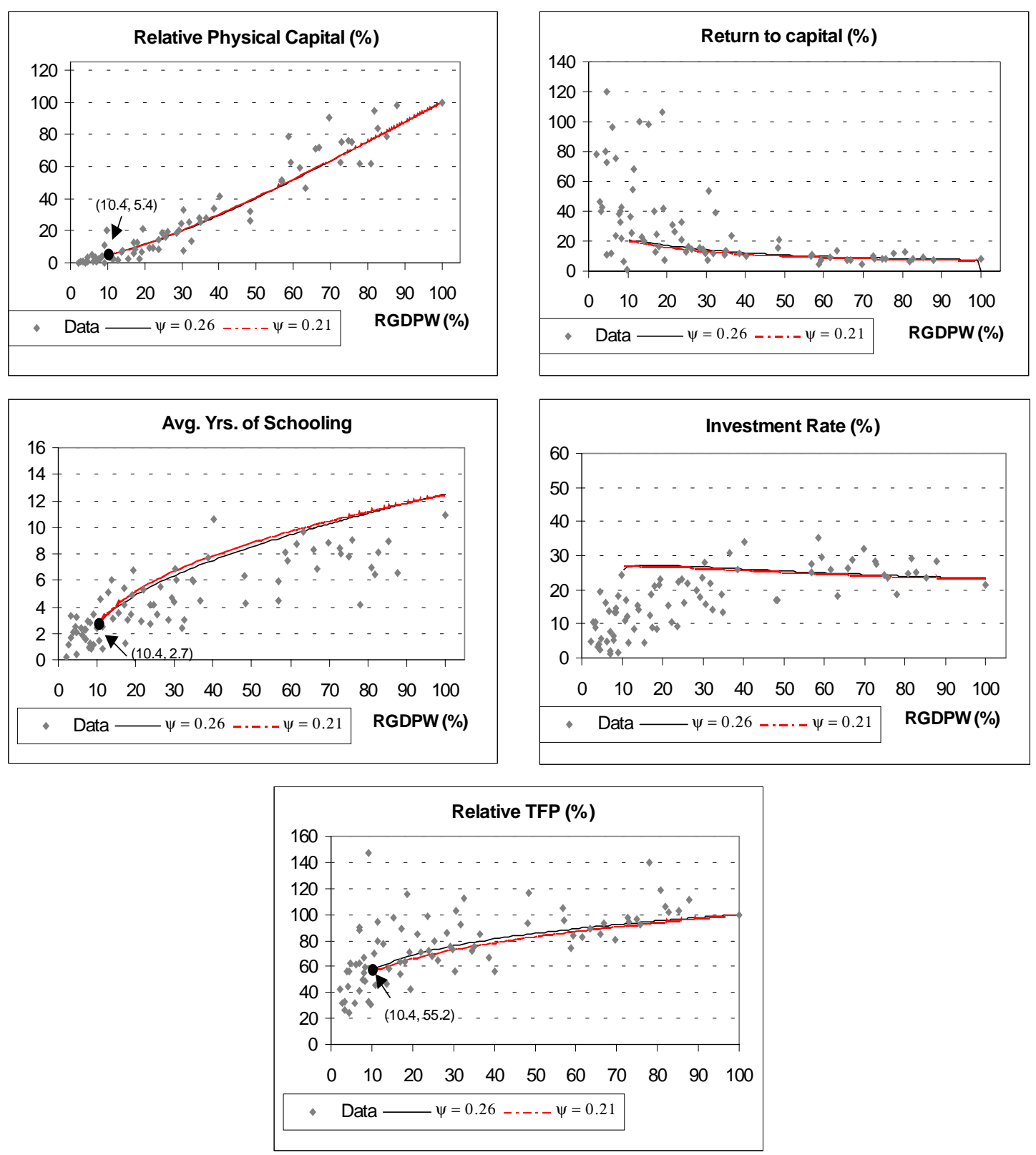

RGDPW is relative GDP per worker. 
cloud in between. The primary " nding is that the simulated dynamics seem to ${ }^{-} t$ well across the observations. Figure 2 illustrates a number of other points worth noting. F irst, notice that a larger degree of relative backwardness (i.e., a larger value of $\tilde{A}$ ) induces faster technology catch-up, and slower human capital accumulation, making the adjustment paths better ${ }^{-} t$ the data. Second, the simulated physical and human capital levels tend to diverge with respect to the rich countries' data points. This is the result of calibrating the steady state to U.S. numbers. The two variables' divergent processes, however, o ${ }^{\circledR s}$ set each other and as a result, the technology level series captures well the observations. Finally, - gure 2 shows that the predicted interest and investment rates are plausible, even though lower investment ratios and larger returns to capital at early levels of development would better capture the data.

In our ${ }^{-}$rst experiment, we have shown that the transition dynamics predictions of our model - $t$ the cross-country data pretty well. We next turn to our second experiment in which we try to assess quantitatively how well the transition dynamics ${ }^{-} t$ the output per worker data. Since, one of the goals of the paper is to compare the transition dynamics ${ }^{-} t$ of our model with that of steady-state regressions, we need to construct a measure of ${ }^{-} t$ that can be compared with that estimated in level regressions (i.e. MRW).

Taking logs in the steady-state output per worker predicted by the neoclassical growth model, MRW obtain an estimated econometric equation of the form

$$
\log \hat{y}=\hat{\imath 0}+\hat{\imath} \log \hat{k}+\hat{\imath 2} \log \hat{S}+" ;
$$

where $\hat{y}$ is output per worker level; $\hat{k}$ and $\hat{S}$ represent estimates of $k$ and $S$, respectively, derived from steady-state conditions using investment rates; $\hat{\imath} \hat{i}^{\prime} s$ are estimated coe \pm cients; and " is a random disturbance term. Evidently, in order for the underlying model to be consistent with the data, estimated coe \pm cients must be plausible according to the weight assigned by the national accounts to the di ßerent inputs. In M RW, to each combined value $(\hat{\imath} \log \hat{k}+\hat{\imath} \log \hat{S})$ the regression assigns a predicted output level in log-scale, and all of the predicted output levels are in turn translated into a measure of ${ }^{-} t$ (the OLS $^{2}{ }^{2}$ ).

Following an equivalent procedure, we ${ }^{-}$rst calculate for each country the combined value $\left.\mathrm{e}^{\mathrm{f}(\mathrm{S})\left(\mathrm{I}_{\mathrm{i}}{ }^{\circledR}\right)}\left[K \neq \mathrm{L}_{\mathrm{A}}+\mathrm{L}_{Y}\right)\right]^{\circledR}$ implied by the data, imposing the calibrated parameter values. Notice that this extended state variable represents the per worker human capital term (i.e. $\left.e^{f(S)\left(1_{i}{ }^{\circledR}\right)}\right)$, and the per worker physical capital term (i.e. $\left.\left[K \neq L_{A}+L_{Y}\right)\right]^{\circledR}$ ), as speci- ed in the production function 
Figure 3: Transition dynamics predictions of GDP per worker for 51-nation sample

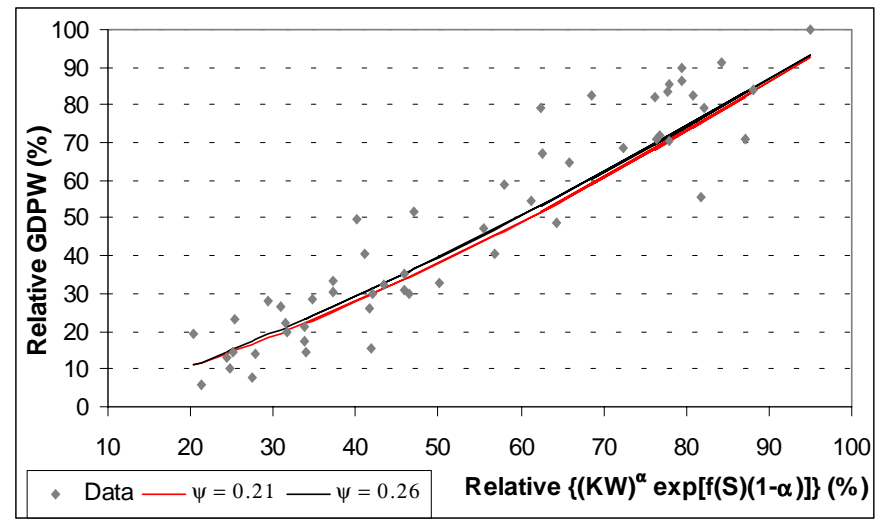

Note: GDPW and K W denote GDP per worker and physical capital per worker, respectively.

given by equation (7). Second, to each nation's value of the combined state variable, we assign the output per worker level $Y \neq L_{A}+L_{Y}$ ) predicted by the transition path. ${ }^{21}$

The special characteristics of the second experiment require that our original sample of 79 countries is reduced to 51. A s mentioned previously, to generate the adjustment path simulation, we employ initial values for the relative physical capital stock per worker and the average educational attainment of 5:4 percent and 2:7 years, respectively. It works out that these two initial values imply a minimum value of the relative extended state-variable of 18:9 percent. The sample that we employ to compute the measure of ${ }^{-} t$ must then consists of those 51 nations that provide values of the extended state variable above 18:9 percent. As expected, 21 of those countries belong to the OECD group; the MRW's 22-OECD minus I reland. ${ }^{22}$

Figure 3 displays the actual output data (plot), and the predicted output data for the two values of $\tilde{A}$ (continuous lines). To assess the ${ }^{-} t$ of the adjustment paths, we employ the following statistic which is equivalent to the OLS $\mathrm{R}^{2}$ :

$$
\text { Pseudo-R } R^{2}=1 \text { i } P_{j=1}^{P_{3}^{N} x_{j} i \frac{1}{N}{ }_{p=1}^{N}\left(x_{j} i x_{j}\right)^{2}},
$$

where $\hat{x}_{j}$ and $x_{j}$ are the predicted and actual values of variable $x$ for country $j$, respectively; and $\mathrm{N}$ is the number of countries included in the sample. Our variable $\mathrm{x}$ must be the natural log of

\footnotetext{
${ }^{21}$ B ecause the simulated adjustment path is a discrete set of couples ${ }^{i} e^{f(S)\left(1_{i}{ }^{\circledR}\right)}\left[K=\left(L_{A}+L_{Y}\right)\right]^{\circledR} ; Y=\left(L_{A}+L_{Y}\right)$, we use interpolation methods to generate the predicted output level.

${ }^{22} \mathrm{An}$ asterisk identi ${ }^{-}$es these 51 nations in the data table contained in the A ppendix.
} 
Table 3: Measure of ${ }^{-} t$ for transition dynamics predictions of log-GDP per worker

\begin{tabular}{lrl}
\hline \hline \multirow{2}{*}{ Country groups } & \multicolumn{2}{c}{ P seudo- $\mathrm{R}^{2}$} \\
& $\tilde{\mathrm{A}}=0: 21$ & $\tilde{\mathrm{A}}=0: 26$ \\
\hline 51-country sample & $0: 759$ & $0: 781$ \\
21-OECD & $0: 747$ & $0: 784$ \\
\hline \hline
\end{tabular}

relative GDP per worker to make the pseudo- $R^{2}$ comparable to the $R^{2}$ reported by steady-state regressions.

For the adjustment path predictions expressed in natural logs, table 3 reports estimates of the pseudo- $R^{2}$. As it is shown, the transition path can explain up to 78 percent of the relative output per worker variation in both the 51 non-oil and the 21 OECD samples. These numbers compare pretty well with the $\mathrm{R}^{2}$ obtained by steady-state regressions. For example, $\mathrm{MRW}$ report a maximum $\mathrm{R}^{2}$ of 78 percent for their non-oil sample, and 28 percent for the OECD group. Nonneman and Vanhoudt (1996), who extend the MRW regression to include an $R \& D$ measure as explanatory variable, obtain an $\mathrm{R}^{2}$ of 73 percent for OECD nations, which is still a little lower than the one delivered by the transition predictions.

How can one interpret our results in the context of the existing empirical literature? Our results imply that the transition dynamics of an $R \& D$ model with endogenous human capital can explain the cross-country output variation as well as the more popular steady-state regressions can. Our - ndings do not discredit in any way the common steady-state regression exercises. They do however provide evidence that transition dynamics maybe important in explaining income di ßerences. The real implication of our result for the empirical growth literature is that by focusing our attention only on the reduced form steady-state predictions we maybe missing a big part of the story of economic growth. 


\section{CONCLUSION}

In this paper we have studied the capacity of transition dynamics to explain income disparities across nations. We have done so within a growth framework of technology progress, physical capital accumulation, and human capital formation. Our main - nding is that the dynamics of the model ${ }^{-} \mathrm{t}$ the cross-country output per worker data at least as well as steady-state regressions. Furthermore, the model has achieved this using the same parameterization that reproduce (a) the J apanese and Korean rapidly growing experiences, and (b) an asymptotic speed of convergence that is consistent with most estimates reported in the empirical growth literature.

O ur results suggest that interpreting the lack of absolute convergence as implying that countries are close to their steady state, and using this argument to justify level regressions based on steadystate conditions (of the MRW type) is unfounded. We ${ }^{-}$nd that the traditional view of a world in which nations move along their distinct balanced-growth paths is as likely as the one in which countries move along adjustment paths toward a common (very long-run) steady state.

The implication of the paper for future research is twofold. First, transition dynamics analysis must play a bigger role in discriminating among alternative theories of growth, especially given the great improvements achieved on numerical algorithms. Second, from a more empirical viewpoint, the potential payo ${ }^{\circledR}$ of ${ }^{-}$nding ways to better integrate steady state and transition dynamics conditions can be high, especially in level regression analysis. Indeed, some researchers, e.g. J ones (2000), have already begun to venture along this path. 


\section{DATA APPENDIX}

\section{Data sets and computer programs}

The data and programs used in this paper are available by the authors upon request.

2 Income (GDP) and its components [Source: PWT 5.6]

Cross-country GDP per worker and real investment shares are taken from the Penn World Tables (PWT), Version 5.6 as described by Summer and Heston (1991). This data set is available on-line at: http:// datacentre.chass.utoronto.ca/ pwt/ index.html.

2 Physical capital stocks [Source: STARS, PWT 5.6, and perpetual inventory approach]

For the non-oil cross-country sample, we follow the perpetual inventory approach. The capital stock is calculated by summing investment from its earliest available year (1960 or before) to 1986 with the depreciation rate set at 6 percent. The initial capital stock is determined by the initial investment rate, divided by the depreciation rate plus the growth rate of investment during the subsequent ten years. In the calibration of the parameter $\tilde{A}$, the J apanese physical capital stock in 1960 and S. Korean physical capital in 1963 are obtained by de ating the 1965 PWT data (which unfortunately do not extend to 1960), using growth rates implied by the STARS physical capital data.

2 Labor force [Source: PWT 5.6]

The cross-country data set on the labor force is also taken from the Penn World Table, Version 5.6.

2 Education [Source: STARS (World Bank)]

Annual data on educational attainment are the sum of the average number of years of primary, secondary and tertiary education in labor force. These series were constructed from enrollment data using the perpetual inventory method, and they were adjusted for mortality, drop-out rates and grade repetition. For a detailed discussion on the sources and methodology used to build this data set see Nehru, Swanson, and Dubey (1995).

2 Return to capital

A nnual data on return to capital $\left(r_{t}\right)$ is calculated as

$$
r_{t}=(1 ; @) \frac{Y}{K}:
$$

\section{Countries in the comprehensive sample}

Our comprehensive sample includes the 79 countries from the Mankiw, Romer and Weil (1992) non-oil sample for which annual data on income, raw labor, human capital, and investment rates were available for every year of the M RW sample period, $1960 \mathrm{i} 1985$. The table below provides a list of these nations along with the $1960 ; 85$ average value of relevant variables for each country. An asterisk $\left({ }^{a}\right)$ denotes the 51 nations included in the sample used to carry out the second experiment. 
Mean values of relevant variables for 79 countries

\begin{tabular}{|c|c|c|c|c|}
\hline Country & $\begin{array}{l}\text { GDP per } \\
\text { worker } \\
\text { (bill. US\$) }\end{array}$ & $\begin{array}{c}\text { Capital } \\
\text { per w. } \\
\text { (bill. US\$) }\end{array}$ & $\begin{array}{c}\text { Educational } \\
\text { Attainment } \\
\text { (years) }\end{array}$ & $\begin{array}{c}\text { Investment } \\
\text { over GDP } \\
(\%)\end{array}$ \\
\hline Algeria & 9590.3 & 19927.6 & 2.40 & 21.81 \\
\hline Argentina & 14514.6 & 25128.8 & 6.30 & 17.09 \\
\hline A ustralia & 24598.2 & 73327.1 & 6.48 & 29.05 \\
\hline A ustria ${ }^{\alpha}$ & 18550.5 & 45706.7 & 8.71 & 25.81 \\
\hline Bangladesh & 3455.2 & 1698.0 & 2.52 & 4.51 \\
\hline Belgium ${ }^{\infty}$ & 22559.7 & 58855.3 & 7.84 & 24.15 \\
\hline Bolivia & 5131.9 & 9916.2 & 4.14 & 18.77 \\
\hline Brazil $^{\infty}$ & 8571.2 & 14648.2 & 3.04 & 19.88 \\
\hline Cameroon & 2116.8 & 1165.5 & 1.58 & 7.78 \\
\hline Canada ${ }^{\infty}$ & 25663.6 & 60720.3 & 8.91 & 23.31 \\
\hline Chile $^{x}$ & 10404.8 & 21791.6 & 5.98 & 18.69 \\
\hline China & 1378.9 & 2877.9 & 3.22 & 19.61 \\
\hline Colombia & 7657.8 & 12274.0 & 3.43 & 16.10 \\
\hline Costa Rica & 9195.0 & 5566.6 & 6.01 & 15.65 \\
\hline Cyprus ${ }^{\not}$ & 9114.0 & 25260.0 & 6.85 & 27.97 \\
\hline Denmark ${ }^{\infty}$ & 19857.8 & 54802.1 & 8.31 & 26.37 \\
\hline Ecuador ${ }^{\alpha x}$ & 7451.9 & 14550.8 & 4.11 & 22.93 \\
\hline Egypt & 4643.7 & 1699.1 & 3.51 & 4.57 \\
\hline El Salvador & 5627.3 & 1821.6 & 3.43 & 8.45 \\
\hline Ethiopia & 647.9 & 290.8 & 0.23 & 4.95 \\
\hline Finland ${ }^{\infty}$ & 17654.8 & 61188.7 & 8.08 & 35.38 \\
\hline France $^{\alpha}$ & 21948.0 & 58143.7 & 7.98 & 27.47 \\
\hline Germany $^{\alpha}$ & 21868.3 & 48559.8 & 8.43 & 28.57 \\
\hline Ghana & 2329.7 & 1901.5 & 2.86 & 6.34 \\
\hline Greece $^{x}$ & 11610.7 & 26284.0 & 7.68 & 25.99 \\
\hline Guatemala & 7117.2 & 6729.0 & 2.66 & 9.40 \\
\hline Haiti & 1861.3 & 792.7 & 1.85 & 4.97 \\
\hline Honduras ${ }^{\alpha}$ & 4257.4 & 5934.4 & 3.16 & 14.16 \\
\hline Iceland ${ }^{\infty}$ & 17861.0 & 48412.5 & 7.46 & 29.60 \\
\hline India & 2056.9 & 2587.4 & 2.28 & 13.63 \\
\hline Indonesia & 2504.2 & 2496.9 & 2.81 & 14.64 \\
\hline Israel ${ }^{\infty}$ & 17082.7 & 39880.0 & 4.50 & 27.55 \\
\hline Italy & 20119.9 & 55748.5 & 6.89 & 28.71 \\
\hline Ivory Coast & 3429.1 & 2051.2 & 0.84 & 12.07 \\
\hline J amaica ${ }^{\infty}$ & 5866.5 & 16367.1 & 6.80 & 22.97 \\
\hline J apan & 12085.7 & 31960.9 & 10.64 & 33.93 \\
\hline ordan ${ }^{x}$ & 9771.7 & 10174.4 & 2.97 & 14.12 \\
\hline Kenya & 1760.3 & 3615.8 & 2.36 & 16.32 \\
\hline Korea. R ep ${ }^{\alpha}$ & 5766.5 & 5231.2 & 4.93 & 21.44 \\
\hline
\end{tabular}

Note: * denotes the 51 nations included in the sample used to carry out the second experiment. 
M ean values of all variables for all 79 countries, cont.

\begin{tabular}{|c|c|c|c|c|}
\hline Country & $\begin{array}{l}\text { GDP per } \\
\text { worker } \\
\text { (bill. US\$) }\end{array}$ & $\begin{array}{c}\text { Capital } \\
\text { per w. } \\
\text { (bill. US\$) }\end{array}$ & $\begin{array}{c}\text { Educational } \\
\text { Attainment } \\
\text { (years) }\end{array}$ & $\begin{array}{c}\text { Investment } \\
\text { over GDP } \\
(\%)\end{array}$ \\
\hline$\overline{\bar{M} \text { adagascar }}$ & 1706.8 & 344.04 & 3.15 & 1.14 \\
\hline Malawi & 1129.2 & 1332.74 & 3.32 & 8.16 \\
\hline M alaysia ${ }^{\propto}$ & 10581.6 & 22547.62 & 5.77 & 29.54 \\
\hline Mali & 1609.8 & 1007.26 & 0.96 & 5.84 \\
\hline M auritius ${ }^{\alpha}$ & 7338.8 & 8191.28 & 6.37 & 8.36 \\
\hline M exico & 16929.0 & 29987.27 & 5.46 & 14.92 \\
\hline M orocco ${ }^{\alpha}$ & 6379.8 & 6724.14 & 2.14 & 9.98 \\
\hline M ozambique & 1541.0 & 443.78 & 2.20 & 1.36 \\
\hline M yanmar & 1276.8 & 1145.10 & 2.36 & 8.94 \\
\hline Netherlands ${ }^{\alpha}$ & 28218.4 & 78868.48 & 8.25 & 20.40 \\
\hline New Zealand ${ }^{\bowtie}$ & 39480.7 & 39480.79 & 8.38 & 24.44 \\
\hline Nigeria & 3036.2 & 4988.88 & 2.00 & 9.88 \\
\hline Norway & 27407.2 & 89938.15 & 9.29 & 28.68 \\
\hline Pakistan & 4075.2 & 3622.92 & 1.94 & 10.16 \\
\hline Panama & 10140.8 & 21008.28 & 7.01 & 16.76 \\
\hline Paraguay & 6451.4 & 9543.62 & 5.70 & 16.40 \\
\hline Peru & 8605.0 & 18792.87 & 6.12 & 16.90 \\
\hline Philippines ${ }^{\not}$ & 4678.4 & 8643.77 & 7.33 & 16.02 \\
\hline Portugal ${ }^{\infty}$ & 11464.4 & 28693.64 & 5.34 & 21.02 \\
\hline R wanda & 1567.2 & 561.09 & 2.64 & 6.12 \\
\hline Senegal & 2638.8 & 1640.40 & 1.75 & 3.56 \\
\hline Sierra Leone & 991.6 & 174.71 & 1.92 & 1.38 \\
\hline Singapore ${ }^{\infty}$ & 17883.6 & 48914.37 & 6.77 & 38.80 \\
\hline Spain & 21162.8 & 59324.44 & 6.79 & 21.84 \\
\hline Sri Lanka & 1943.2 & 2363.75 & 6.01 & 12.40 \\
\hline Sudan & 2605.6 & 3923.26 & 1.57 & 13.40 \\
\hline Sweden ${ }^{\infty}$ & 25875.4 & 70883.61 & 9.63 & 19.66 \\
\hline Switzerland ${ }^{\not}$ & 29446.0 & 101275.38 & 6.73 & 28.60 \\
\hline Tanzania & 967.4 & 1097.57 & 2.02 & 10.80 \\
\hline Thailand ${ }^{\infty}$ & 4657.4 & 6973.21 & 5.45 & 16.74 \\
\hline Tunisia & 8629.6 & 11304.46 & 4.48 & 13.36 \\
\hline Turkey & 7009.6 & 15438.82 & 4.22 & 22.14 \\
\hline Uganda & 1637.6 & 431.07 & 2.39 & 1.82 \\
\hline U.K. ${ }^{\infty}$ & 22472.8 & 47706.21 & 9.94 & 16.60 \\
\hline U.S. & 32684.6 & 83918.58 & 11.35 & 21.14 \\
\hline Uruguay ${ }^{\not}$ & 10773.0 & 24664.08 & 7.53 & 12.84 \\
\hline Venezuela $a^{x}$ & 19210.6 & 47992.71 & 6.02 & 15.48 \\
\hline Zaire & 1171.6 & 721.89 & 3.67 & 5.60 \\
\hline Zambia & 2493.6 & 8950.54 & 4.06 & 9.52 \\
\hline Zimbabwe $e^{x}$ & 3271.0 & 6270.08 & 4.36 & 12.34 \\
\hline
\end{tabular}




\section{REFERENCES}

Attanasio, O. and Weber, G., IC onsumption, the Interest Rate and Aggregation," Review of E conomic Studies, 60:631-649, 1993.

Barro, R. and Lee, J II International comparisons of educational attainment," J ournal of M onetary E conomics, 32:363-394, 1993.

Barro, R. and Sala-i-M artin, M., E conomic Growth, M cG raw Hill, 1995.

Bils, M. and Klenow, P., \Does Schooling Cause Growth?" American economic Review, forthcoming.

Caballe, J. and Santos, M., IOn endogenous growth with physical and human capital," J ournal of Political E conomy, 101:1042-1067, 1993.

Chari, V.V., K ehoe P. and M CGrattan E., IT he Poverty of Nations: A Quantitative Exploration," NBER working paper \# 5414, 1996.

Christiano, L., I Understanding J apan's Saving Rate: The Reconstruction Hypothesis," Federal Reserve of M inneapolis Quarterly R eview, 2:10-29, 1989.

Dinopoulos, E., and P. Thompson. \Endogenous Growth in a Cross-Section of Countries." J ournal of International E conomics 51:335-362, 2000.

Easterly, W., K remer, M., Pritchett, L. and Summers, L., I Good Policy or Good L uck? Country Growth Performance and Temporary Shocks," J ournal of M onetary E conomics, 32:459-483, 1993.

Eicher, T., and Turnovsky, S., \A Generalized Model of Economic Growth," Economic J ournal 109:394-415, 1999a.

Eicher, T ., and Turnovsky, S., I Convergence in a T wo-Sector N on-Scale G rowth M odel, " J ournal of Economic Growth 4:413-429, $1999 \mathrm{~b}$.

Eicher, T., and Turnovsky, S., I Transition Dynamics in N on-Scale M odels," J ournal of Economic Dynamics and Control, forthcoming

Funke, M. and Strulik, H., IOn Endogenous Growth with Physical Capital, Human Capital and Product Variety," E uropean E conomic R eview, 44:491-515, 2000.

Gerschenkron, A., I E conomic Backwardness in Historical Perspective," Cambridge, Harvard University P ress, 1962.

Griliches, Z, IProductivity Puzzles and R\&D: A nother Nonexplanation," J ournal of Economic Perspectives, 2:9-21, 1988.

Hall, R., IIntertemporal Substitution in Consumption," J ournal of Political E conomy, 96:339-357, 1988.

J ones, $C ., \backslash R \& D$-Based M odels of E conomic Growth," J ournal of Political E conomy, 103:759-784, 1995.

J ones, C., \Human Capital, Ideas, and E conomic Growth," Stanford University, mimeo, 1996.

J ones, C., । Convergence R evisited," J ournal of E conomic Growth, 2:131-153, 1997.

J ones, C., ISources of U.S. E conomic Growth in a World of Ideas, " mimeo, Stanford University, 2000 .

J ovanovic, J . and Rob, R., ISolow vs. Solow," working paper, NY U, 1998. 
J udd, K, \Projections Methods for Solving A ggregate Growth Models," J ournal of Economic Theory, 58:410-452, 1992.

King, R. and Rebelo, S., ITransitional Dynamics and Economic Growth in the Neoclassical Model," A merican Economic Review, 83:908-931, 1993.

K lenow, P. and Rodriguez-Clare, A., \Economic Growth: A Review Essay," J ournal of Monetary E conomics, 40:597-617, 1997.

K rueger, A. and Lindahl, M., IEducation for Growth in Sweden and the World," working paper, Princeton University, 1998.

Mankiw, G., Romer, D. and Weil, D., \A Contribution to the Empirics of Economic Growth," Quarterly J ournal of E conomics, 107:407-437, 1992.

Mincer, J ., Schooling, Experience and Earnings, Columbia University Press, 1974.

Mulligan, C. and Sala-i-Martin, X., ITransitional Dynamics in T wo-Sector M odels of Endogenous Growth," Quarterly J ournal of E conomics, 108:739-773, 1993.

Nelson, R. and Phelps, E., IInvestment in Humans, Technological Dißusion, and Economic Growth," A merican Economic Review, 56:69-83, 1966.

Nehru, V., Swanson, E. and Dubey, A., \A New Database on Human Capital Stocks in Developing and Industrial Countries: Sources, Methodology and Results," J ournal of Development E conomics, 46:379-401, 1995.

N onneman, W . and Vanhoudt, P., \A Further A ugmentation of the Solow M odel and the Empirics of E conomic G rowth for OECD Countries," Quarterly J ournal of E conomics, 3:943-953, 1996.

Ortigueira, S., and Santos, M., 1 On the Speed of Convergence in Endogenous Growth M odels," A merican Economic Review, 87:383-399, 1997.

Papageorgiou, C. and Perez-Sebastian, F., I Growth Miracles Reexamined," working paper, LSU, 2000.

Parente, S.L. and Prescott, E.C., \Barriers to Technology Adoption and Development." J ournal of Political Economy, 102:298-321, 1994.

Perez-Sebastian, F., ITransitional Dynamics in an $R \& D$-Based Growth Model with Imitation: Comparing its P redictions to the Data," J ournal of M onetary E conomics, 42:437-461, 2000.

Psacharopoulos, G., IReturns to Investment in Education: A Global Update," World Development, 22:1325-1343, 1994.

Sala-i-M artin, X. IT he Classical A pproach to Convergence A nalysis," E conomic J ournal, 106:10191036, 1996.

Summer, R. and Heston, A., IT he Penn World Table (M ark 5): A n Expanded Set of International Comparisons: 1950-1988," Quarterly J ournal of E conomics, 106:327-368, 1991.

Temple, J.R.W., $\backslash$ Robustness Test of the Augmented Solow Model," J ournal of Applied Econometrics, 13:361-375, 1998.

Veblen, T., Imperial Germany and the industrial revolution, Macmillan, New York, NY, 1915. 